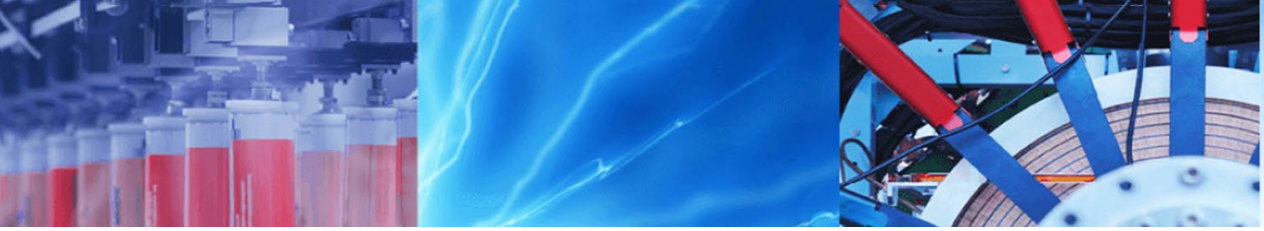

Research Article

\title{
Energy dissipation evaluation for stepped spillway using a fuzzy inference system
}

\author{
Alireza Mojtahedi ${ }^{1}$ (D) Nasim Soori ${ }^{1} \cdot$ Majid Mohammadian $^{2}$
}

Received: 30 March 2020 / Accepted: 24 July 2020 / Published online: 1 August 2020

(c) Springer Nature Switzerland AG 2020

\begin{abstract}
In this study, to evaluate the effects of geometry parameters on the dissipation rate in flows over the stepped spillways, a numerical model is provided and validated by using a physical model. A type of Fuzzy Inference System (FIS) is used to study the control of the rates of dissipation. It is used to measure the estimated energy dissipation under different scenarios, and the results are compared with prepared numerical database. An error criterion is used to examine the prediction accuracy of the FIS measurements. The realization of these kinds of considerations may, in turn, lead to a remarkable reduction in the dimensions of stilling basins. The results indicate that proposed FIS can be used as a valuable tool for operational control of dissipater structures with consideration of different geometric parameters. The method is proposed somehow to consider the uncertainty problems with consideration of the benefits, and some shortcomings noted in the literature.
\end{abstract}

Keywords Fuzzy inference system · Numerical simulation · Physical model · Image processing system · Stepped spillway

$\begin{array}{ll}\text { Abbreviations } \\ \text { FIS } & \text { Fuzzy inference system } \\ \text { CFD } & \text { Computational fluid dynamics } \\ \text { MAPE } & \text { Mean absolute percentage error } \\ E D \triangle \mathrm{H} & \text { Rate of energy dissipation } \\ H_{\max } & \text { Maximum head available } \\ \mathrm{H}_{\text {dam }} & \text { Height of dam } \\ H & \text { Height of steps } \\ D_{H} & \text { Hydraulic depth of flow } \\ I & \text { Length of steps } \\ Q & \text { Discharge rate } \\ N & \text { Number of steps } \\ a & \text { Negative slope on each step } \\ y_{C} & \text { Critical depth }\end{array}$

\section{Introduction}

One main challenge in spillway design considerations is to arrive at a design which is able to pass discharge floods of a wide range of magnitudes without significant scouring below the dam toe, [1]. Stepped spillways are one type of energy dissipator in which the flow energies are reduced by a cascading series of hydraulic jumps and the impacts on the surface of the steps. These advantages of significantly increase in rate of energy dissipation have created increasing interest in stepped spillways, [2]. The advent of technologies like roller-compacted concrete has also created interest in more detailed studies on spillway, [2-5].

One of the most attractive factors of selecting a stepped spillway over the other chutes is the enhanced energy dissipation that takes place in the spillway chute, [6, 7]. The rate of energy dissipation may be presented as fundamental parameters for designing stepped spillways [8]. The energy dissipation over vertical free fall and stepped

Alireza Mojtahedi, a.mojtahed@tabrizu.ac.ir | ${ }^{1}$ Faculty of Civil Engineering, University of Tabriz, Tabriz, Iran. ${ }^{2}$ Faculty of Engineering, University of Ottawa, Ottawa, Canada. 
drops was studied via experimental models, and the results showed that the energy dissipation increased with total drop height [9]. The energy dissipation over stepped spillway was measured by using a physical model and concluded that for small dams with low flow rates, a stepped spillway dissipates more kinetic energy than other types [10]. The effect of some parameters such as flow rate and number of steps on energy dissipation was examined [11]. The energy dissipation rate was studied over stepped spillways using experimental measurements and compared the results of tests with other research works [12]. The ability of the circular crested stepped spillways was investigated. The performance showed the energy of flow more dissipates at this structure than the smooth chute at the same range of discharge [13]. The hydraulic jump characteristics and energy dissipation at downstream of stepped weir were examined. The results showed that by increasing the steps number the energy dissipation is increased [14].

Several researchers have performed studies on physical models of stepped spillways, but the obtained results are usually only valid for individual cases and can only be used as guides for similar situations. Fortunately, with the development of high-performance computers, the computational fluid dynamics (CFD) technique has been developed. Many studies have used CFD to simulate flows over a stepped spillway (see $[15,16]$ as examples). The effect of scale ratio in a nappe flow regime was studied using numerical simulation and then compared with that of other researchers [17]. Numerical method was used to simulate flow over the stepped spillway. The results show that CFD technique is an efficient method to simulate turbulent [18]. In recent years, the number of studies which has applied types of soft computing techniques in order to evaluation of the performance of steppes spillway has increased (see for example, [19]. The capability of neural computing approaches was assessed to predict energy dissipation over the stepped spillway by using data configurations of the physical model [20]. Support vector machine regression was used to estimate the energy dissipation in a stepped spillway, and results indicated that the model was successful in predicting the energy dissipation of stepped spillways [21]. Recently, different attempts have been made to use intelligent methods for studying open channel hydrodynamics [22].

The above mentioned review of the literature implies that the parameters related to energy dissipation rates have received more attention due to the importance of the problem. In general, the geometric parameters of a stepped spillway consist of two components of the number of steps, and adverse slopes. The configurations of these two components have a significant impact on how the spillway reacts. One main aim of this study is to investigate the effects of the effective geometry parameters on flows over a stepped spillway with respect to energy dissipation rates, and the results show that the number of steps must be considered as the main parameter to evaluate the flow conditions. On the other hand, as noted in the literature, the many practical problems caused by various types of uncertainty make it a complicated issue and, there is no report that directly focuses on the effects of the uncertainties. The main objective of this study is to involve these major problems by utilizing well-known techniques for spillway design. Consequently, the problem is to scrutinize a robust system that can consider the uncertainties and the effects of nonlinearity on the relationships between the dominant parameters. The advantages of the method are applicable for reducing the time taken in experimental and numerical modeling for different spillway configuration scenarios. For this purpose, combined algorithmic incorporation of a fuzzy logic system (FIS) and CFD modeling is used to study the effects of the effective parameters on the energy dissipation in a physical model. For this purpose, a physical model of a stepped spillway is used to obtain the experimental results. Then, a numerical model is updated based on the observed results, and run for different geometries. Finally, the gathered database is used to scrutinize the performance of the developed FIS model. This method has been proposed in order to consider the uncertainty problems with consideration of the benefits and shortcomings noted in the literature. The concept for the method is developed based on the nonlinear geometric characteristics of related system responses and the nonlinearities in the nature of the evaluated system. The results imply that the method can serve as an efficient technique and valuable tool for operational control of dissipater structures such as stepped spillways and to detect the effects of sensitive parameters.

\section{Materials and methods}

\subsection{Model specification, experimental setup, and laboratory measurement}

A hydraulic flume was constructed in the hydraulic laboratory of department of civil engineering, university of Tabriz, Iran to offer generation of steady fluid flows. The flume is supported by a water pump and a pair of rigid pedestals, and a service module incorporating a sump tank and submersible pump provide a source of water which is continuously recirculated through the channel section. The bed and side walls were fabricated using transparent glass sheets with smooth surfaces. The flume is $14 \mathrm{~m}$ long, $1 \mathrm{~m}$ deep and $1 \mathrm{~m}$ wide. A discharge tank with a sluice gate was located at the downstream end of the flume. The physical model of a stepped spillway was 
constructed of metal sheets and installed at a distance of $8 \mathrm{~m}$ from the start point of the flume. The tests were conducted at a water depth of $0.8 \mathrm{~m}$ for the flow of water in the flume. Accordingly, based on the dimensions of the flume and the capacity of the pump, the dimensions were selected as a height $\left(H_{\text {dam }}\right)$ of $40 \mathrm{~cm}$ and length of $100 \mathrm{~cm}$, with a step length of $25 \mathrm{~cm}$. Also, the steps' height and width were $10 \mathrm{~cm}$ and $100 \mathrm{~cm}$ respectively. The test setup and the general view of the model are illustrated in Fig. 1.

In recent years, the use of image-processing techniques for the analysis of experimental results has received special attention because they are able to estimate the parameters without disruption under experimental conditions. Image processing is a technique that extracts data from the recorded images of a semi-transparent environment via a computer based algorithm and converts them to numerical values. The advantages of this method can be seen in different science fields [23]. In this study, profiles of the experimental water surface were obtained by this technique using MATLAB software. To aid in this purpose, water profiles were captured by one high speed camera through the side wall glass. The images were processed by the wavelet transform technique, where the integration was done by the trapezoidal rule. The obtained results showed that the image-processing technique was quite promising in detecting the water surface profiles of this study. Figure 2 depicts the observed results for one of the implemented test cases.

\subsection{Theories and numerical analysis of the flow regimes on a stepped spillway}

The type and size of the spillway mainly selected for designing are primarily dependent upon the site conditions, the purpose of the dam, size and height of the dam, drainage basin and flood potential. In regular and smooth
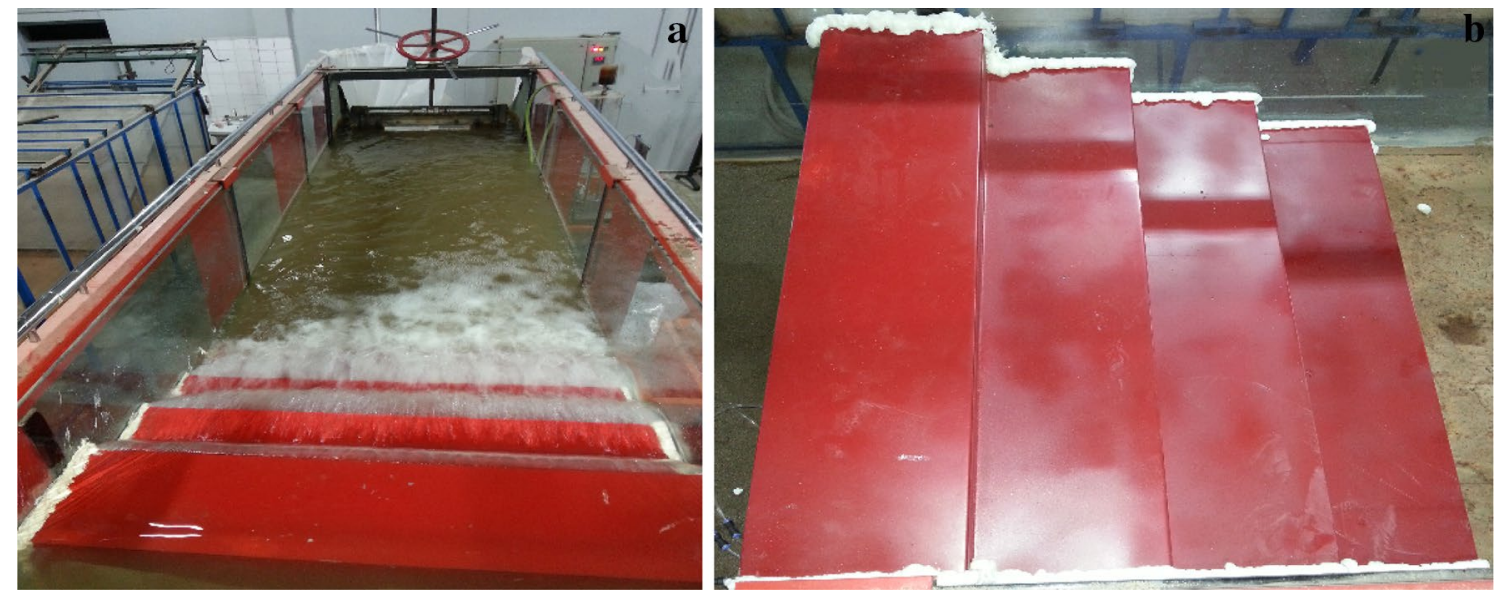

Fig. 1 a General view of the flume and; $\mathbf{b}$ placement of physical model of the stepped spillway

Fig. 2 Measured flow profile over the studied physical model using image processing

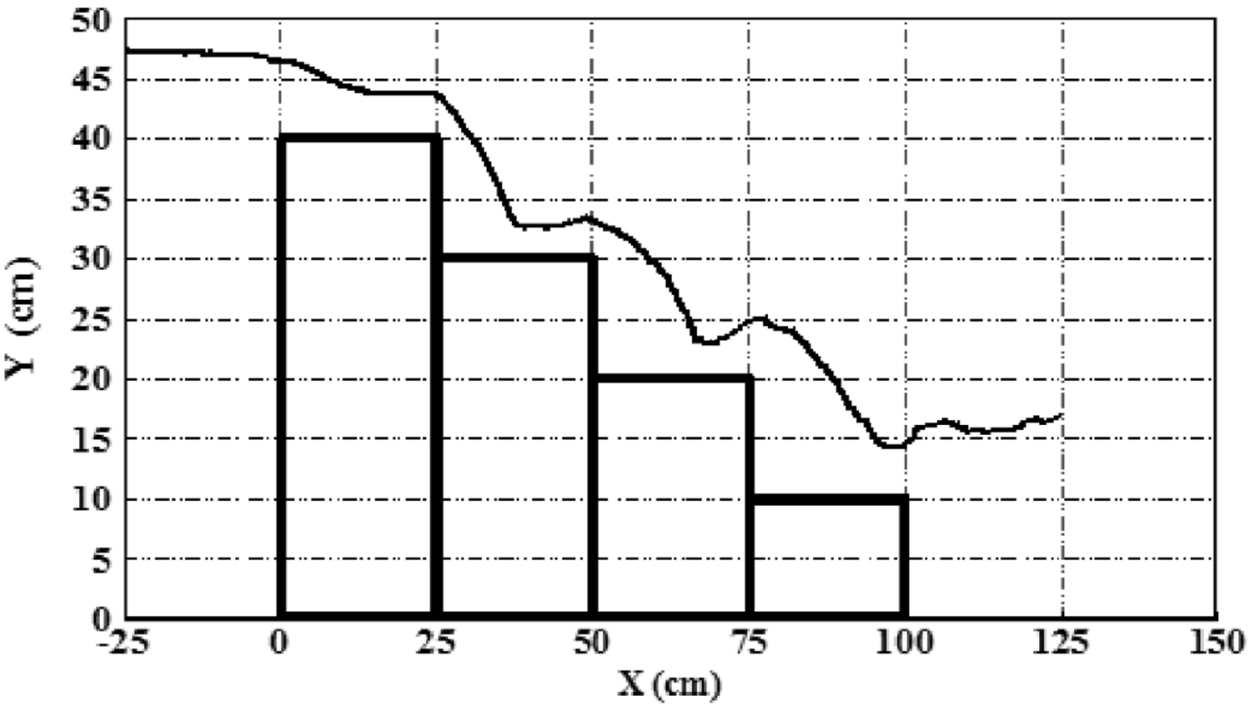

SN Applied Sciences A SPRINGER NATURE journa 
spillways, kinetic energy dissipation occurs predominantly through losses due to friction. Several researchers have produced energy dissipation theories and related equations. For example, Eq. 1 was proposed in order to determine the rate of energy dissipation in nappe flows with hydraulic jumps [6]:

$\frac{\Delta H}{H_{\max }}=1-\left[\frac{0.54\left(\frac{y_{c}}{h}\right)^{0.275}+\frac{3.43}{2}\left(\frac{y_{c}}{h}\right)^{-0.55}}{\frac{3}{2}+\frac{H_{d a m}}{y_{c}}}\right]$

where $H_{\max }=\left(H_{d a m}+(3 / 2) y_{c}\right)$ is the total energy, and $\Delta H$, $y_{c^{\prime}} H_{\text {dam }}$, and $h$ are the dissipated energy over the length of the chute, the critical depth $(\mathrm{m})$, the height of the dam, and the height of the steps $(m)$ respectively.

In this study, the effects of the relevant parameters on the discharge rates over the considered scenarios [8] were evaluated via the rate of energy dissipation which was calculated using Eq. 2:

$E D=\frac{\Delta H}{H_{\max }}=\frac{H_{\max }-H_{1}}{H_{\max }}$

where $H_{\max }$ and $H_{1}=y_{1}+V_{1}^{2} / 2 g$ indicate the energy at upstream and the spillway toe, respectively and $\Delta H$ is the energy dissipation rate, as shown in Fig. 3.

On the other way, CFD considers methods to simulate flow patterns in which standard flow equations such as the Navier-Stokes and continuity equations are discretized and solved for each computational cell [24]. In the present study, a commercial CFD code (Flow-3D) is used to model the flow on a stepped spillway for the considered domain. Flow-3D is a powerful CFD commercial code developed by Flow Science, Inc. and is adequate for solving a wide range of fluid flow patterns [25]. It is based on the finite volume method (FVM) [23]. In this model, the FVM is used to discretize the governing equations in a Cartesian coordinate system. In this software, the geometry and grid generation are free-grid, so they are independent of one another, and changes in either the grid or geometry can be made freely without requiring other changes [26]. For CFD problems, the continuity equation of flow can be considered by Eq. 3 :

$V_{F} \frac{\partial \rho}{\partial t}+\frac{\partial}{\partial x}\left(\rho u A_{x}\right)+\frac{\partial}{\partial y}\left(\rho u A_{y}\right)+\frac{\partial}{\partial y}\left(\rho u A_{y}\right)=0$

where $V_{f}$ is the volume fraction of the fluid, $\rho$ is the fluid density, $u, v$, and $w$ are the velocity components in the $x$, $y$, and $z$ ) directions respectively, and $A_{x}, A_{y}$, and $A_{z}$ are the cross-sectional area of the flow. The momentum equation is also written in a 3-dimensional form as Eq. 4:

$\frac{\partial u}{\partial t}+\frac{1}{V_{F}}\left\{u A_{x} \frac{\partial u}{\partial x}+v A_{y} \frac{\partial u}{\partial y}+w A_{z} \frac{\partial u}{\partial z}\right\}=-\frac{1}{\rho} \frac{\partial P}{\partial x}+G_{x}+f_{x}$

where $P$ is the fluid pressure, $G_{x}$ is the acceleration created by body fluids, $f_{x}$ is the viscosity acceleration through three dimensions, and $V_{F}$ relates to the volume of fluid. The measured results obtained by the Eq. 1 and the studied numerical models are compared with each other in Table 1.

Establishing the validation of the proposed fuzzy-based method requires many data series for different conditions which must be recorded during numerous scenarios for the various model shapes. For this purpose, the investigations in this research relied on two complementary techniques to deal with the related complex fluid flow regimes, which were laboratory measurements, and numerical calculations. It should be mentioned that a disadvantage of the physical models is that they are undeniably more expensive except in rare instances [27]. Therefore, in situations where we can trust that a numerical model can give reliable results with engineering accuracy, it can be the tool of choice. Of course, numerical modeling should be
Fig. 3 Hydraulic parameters required to calculate the rate of energy dissipation [8]

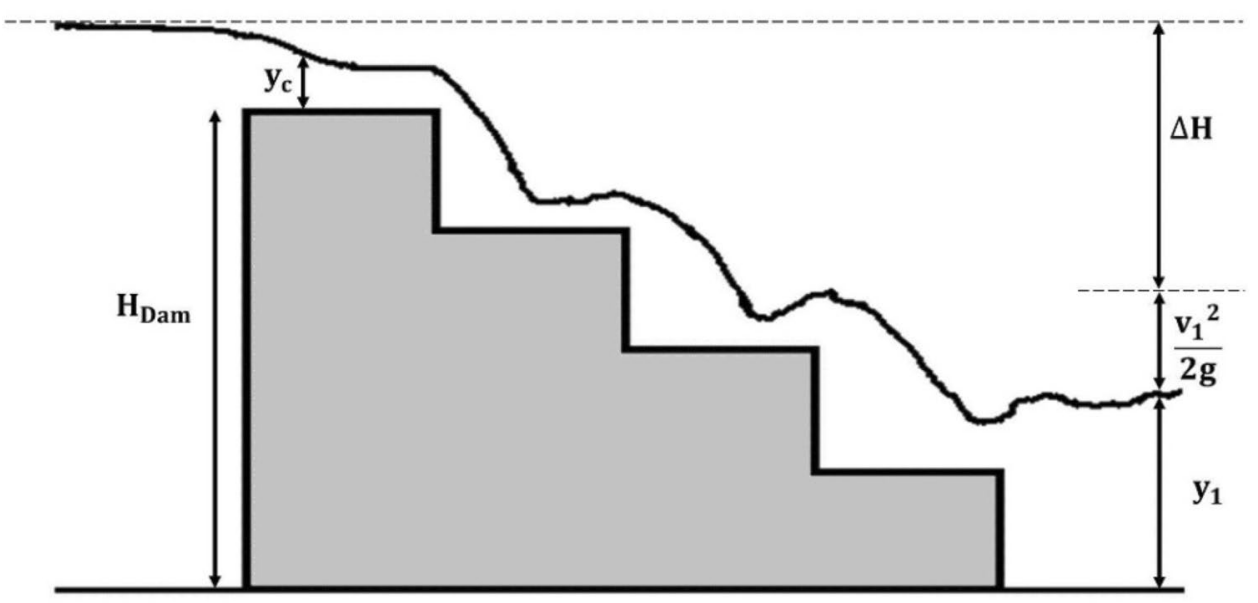


Table 1 Comparison between the measured results obtained by the numerical models and Eq. 1

\begin{tabular}{|c|c|c|c|c|c|c|}
\hline \multirow[b]{3}{*}{ Q } & \multicolumn{6}{|c|}{ (\%) Energy dissipation } \\
\hline & \multicolumn{3}{|c|}{ Numerical model } & \multicolumn{3}{|c|}{ Chanson's equation } \\
\hline & $N=4$ & $N=8$ & $N=10$ & $\mathrm{~N}=4$ & $N=8$ & $N=10$ \\
\hline 0.016 & 63.24 & 69.64 & 73.5 & 75.1 & 81.62 & 83.19 \\
\hline 0.029 & 61.7 & 63.1 & 67.3 & 70.47 & 77.68 & 79.37 \\
\hline 0.035 & 59.2 & 62 & 64.5 & 68.87 & 76.26 & 78 \\
\hline 0.0403 & 53.6 & 57.2 & 56.4 & 67.63 & 75.15 & 76.89 \\
\hline 0.046 & 48.4 & 52.8 & 50.7 & 66.44 & 74.05 & 75.81 \\
\hline
\end{tabular}

Table 2 Geometric characteristics of the stepped spillways for the various numerical models

\begin{tabular}{lll}
\hline Height/length & Number of steps & Slope of steps $\left({ }^{\circ}\right)$ \\
\hline$\frac{h}{l}=0.4$ & 4 & $0,4,8,12$ \\
& 8 & $0,4,8,12$ \\
& 10 & $0,4,8,12$ \\
\hline
\end{tabular}

calibrated through experimental work, but after that, it can provide more insight into the subject via more control in the tests. In this study, a 4-step physical model of the spillway was used to provide repeatable calibration and verification data. Then, the numerical models were run for different geometries of the spillways based on the shapes of the steps. The geometric characteristics of the models are described in Table 2 . The modelling processes were implemented for 5 different rates of flow discharge, including $0.016,0.03,0.035,0.04$, and $0.046 \mathrm{~m}^{3} / \mathrm{s}$. In Table 2 , h and $\mathrm{I}$ are the height and length of the steps, respectively. The numerical models were run for different step geometries, beside the same aspect ratios of 1 to $h$, in order to ensure similarity of the general geometric conditions between the different numerical models and the physical model. Furthermore, the heights in all models $\left(H_{\text {dam }}\right)$ were kept constant for all configurations and scenarios.

The number of meshes and their proportions through the $x, y$, and $z$ directions must be determined using parameters of the maximum adjacent cell size ratio and the maximum aspect ratio, whose proportions must not exceed 1.25 and 3.0, respectively [24]. Therefore, the aspect ratios of individual cells were also checked between the cells and the mesh plans, and all ratios satisfied the recommended neighboring values. Related parameters are shown in Table 3. For the case of the simple geometry of the model, a uniform mesh was used to discretize the studied domain. The maximum adjacent cell size ratios and maximum aspect ratios were chosen as less than 1.25 and 3, respectively, in order to reduce the error related to mesh size. The mesh number was selected as 2,150,000 by using the grid-independent solution. Also, the Re-Normalized Group
Table 3 Mesh types and information

\begin{tabular}{ll}
\hline Maximum aspect ratio & $\begin{array}{l}\text { Maximum } \\
\text { adjacent cell } \\
\text { size ratio }\end{array}$ \\
\hline $\mathrm{X}-\mathrm{Y}$ direction: 2.27 & X direction: 1.25 \\
Y-Z direction: 1.18 & Y direction: 1 \\
Z-X direction: 2.69 & Z direction: 1 \\
\hline
\end{tabular}

(RNG) was chosen by trying different turbulence models in order to evaluate the accuracy of the observed results.

The upstream and downstream boundary conditions were defined as Specified Pressure (with fluid elevation and pressure being defined as hydrostatic) and Outflow, respectively. The bottom boundary was defined as no-slip condition, as shown in Fig. 4, and the top boundary was set as Specified Pressure (with Fluid Fraction $=0$ ). Both remaining boundary conditions were set as Symmetry.

As the other aspect of the experiment, the air-water flow condition and/or a two-phase state could be observed, but at only the lowest step area. Based on this fact, the water profile behaved in a manner similar to an unsteady flow condition with low fluctuations on the surface over the last step and at the start of the downstream area of the experiment. Nevertheless, by considering the low height and the length of the physical chute, it was expected that the mentioned phenomenon could not have a dominant effect on general aspects of the studied flow. The energy dissipation rate of flow had been considered as the main parameter for this study in order to evaluate the efficiency of the proposed soft competing method. With all this, a curved line was fitted for average height of the fluctuating surface profile at the mentioned area to compare the experimental and numerical results. We also controlled the pressure, during the implementation of the test. For this purpose, the manometer measuring instruments used to track the occurrence of negative pressure, as shown in Fig. 5.

The related results also implied that the related effects are not dominant in the numerical modelling process. 
Fig. 4 Considered boundary conditions and geometries for the numerical model
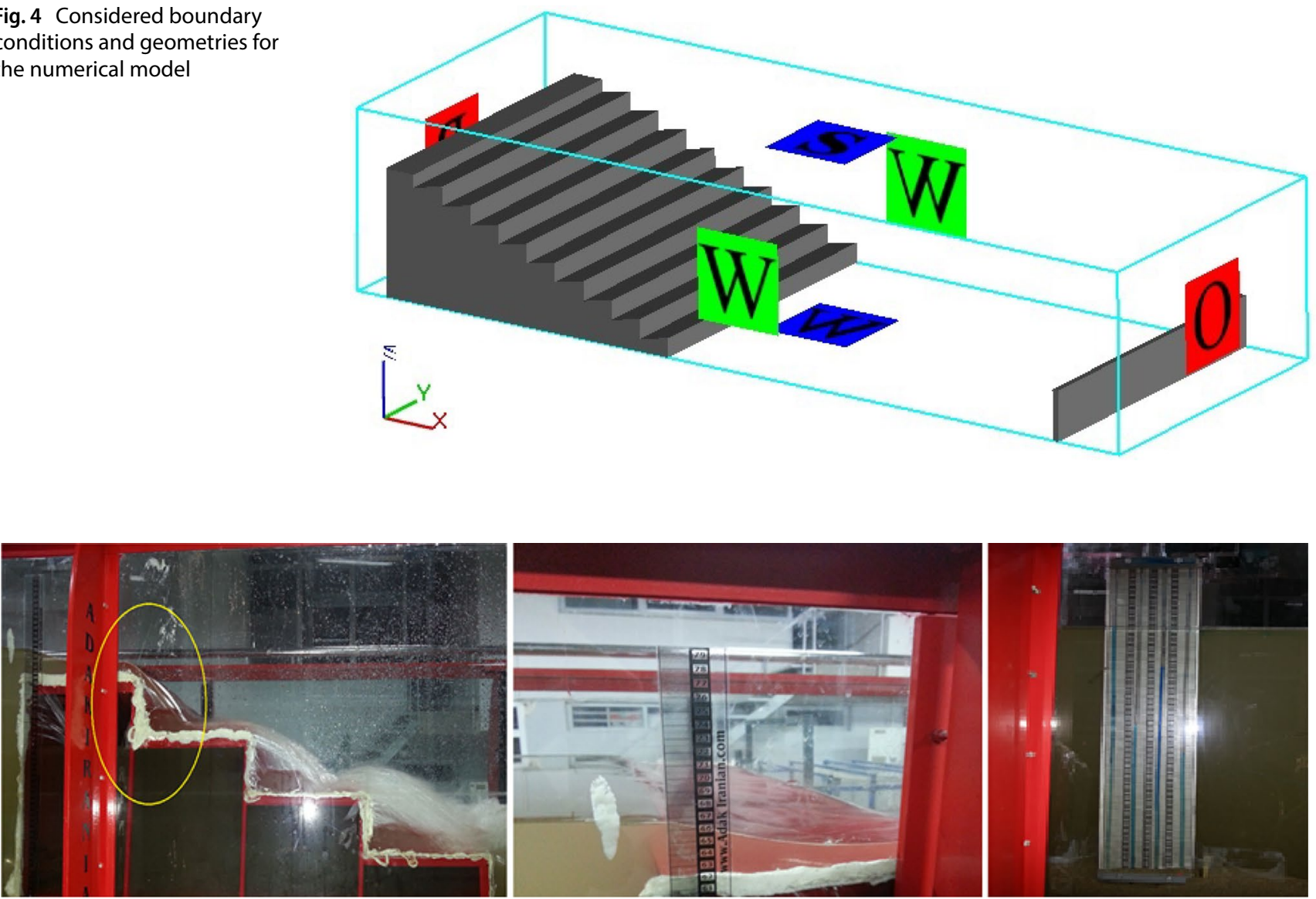

Fig. 5 Flow over the studied model and installed manometer measuring instruments

Therefore, three-dimensional and single-phase flow assumptions were used for the numerical modelling process. The gained results for the water heights at the up and downstream areas showed an acceptable adaptation between the observations and measurements to rely on the assume assumption.

\subsection{Fuzzy inference system and fuzzy-logic modelling}

Two major techniques for developing a statistical model can be implemented as parametric modeling and or probabilistic methods [28]. Fuzzy logic is a logical system that is an extension of multivalued logic. The goal of a FIS is to achieve a relationship between the input and output parameters by using a set of if-then rules. This system can be used as a predictive model when the parameters are vague [29]. In general, any fuzzy system contains the following steps, as shown in Fig. 6: 1) An inference system is defined based on available data, the analysis operation is applied by a fuzzy inference engine. Several FISs can be utilized for this purpose, such as Sugeno and Mamdani's systems, [30]; 2) A membership function definition is converted into fuzzy data (fuzzification) by membership functions; 3 ) Inference rule definitions and combinations; and 4) Obtaining results (defuzzification).

In this study, Mamdani FIS was applied to investigate the energy dissipation in a fluid flow on a stepped spillway. The three nominated fuzzy input variables were considered as $y_{c} / h$, number of steps, and adverse slope of step. Also, the output of the system was the rate of energy dissipation.

\section{Results and discussion}

The purpose of this work is to address the uncertainty problem in the study of relationships between the hydraulic and geometric parameters. A FIS algorithm is used. This algorithm requires many data series for various conditions which must be recorded during numerous scenarios. Certainly, it is impossible to define each of the cases for a physical model, and so a numerical model must be used to evaluate the efficiency of the method. But when the 
Fig. 6 Flowchart of methodologies based on fuzzy concepts [29]

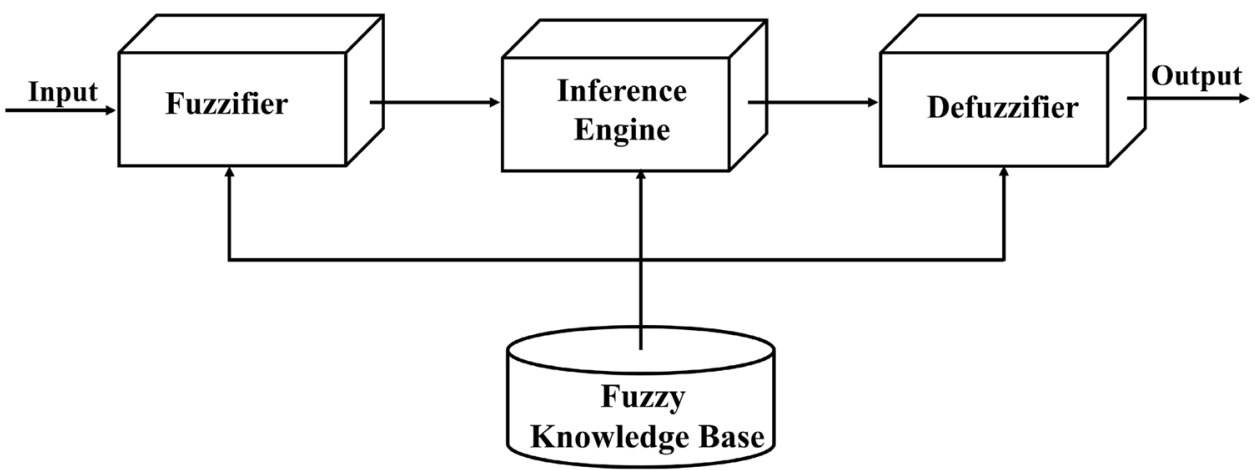

experimental and numerical results are compared to each other, some differences that can produce false alarms are found due to various types of errors [31]. For this reason, in the first step, the acceptability of the numerical model must be assessed. Figure 7, illustrated a sample of the experimental and numerical water surface profiles, for one data recording set. A curved line was fitted for the average height of the surface profile over the last step. Figure 7 can be utilized as an indication of the validation criteria for acceptance of the numerical results, and demonstrates the appropriateness of the obtained numerical results.

\subsection{Preliminary results for sensitivity analysis and energy dissipation characteristics}

In this section, the stepped spillway configurations are examined by considering different negative step slopes (adverse steps), different numbers of steps $(N)$, and ratios of critical depth to step height $\left(y_{c} / h\right)$ using the calibrated numerical model. Five discharge values were considered.
The heights in all models $\left(H_{\text {dam }}\right)$ were kept constant for all the configurations and scenarios. In this regard, the rate of energy dissipation (ED) is calculated using Eq. 2. The numerical results for spillways with 4 steps and a discharge of $Q=0.03 \mathrm{~m}^{3} / \mathrm{s}$ are illustrated in Fig. 8 .

The empirical observations prove that the energy dissipation is a function of the flow regime type and the discharge rate. A formula is presented to predict the upper limit of a nappe flow and the lower limit of a skimming flow, as follows [32]:

$\left(\frac{y_{c}}{h}\right)=0.89-0.4\left(\frac{h}{l}\right) \quad$ Lower limit of transition flow

$\left(\frac{\mathrm{y}_{\mathrm{c}}}{\mathrm{h}}\right)=1.2-0.325\left(\frac{\mathrm{h}}{\mathrm{l}}\right) \quad$ Upper limit of transition flow

Both of these equations were used for flat steps with $0.05 \leq h / l \leq 1.7$ (where $h$ and $/$ are the horizontal length
Fig. 7 Comparison between the observed and numerical results of the free surface

\section{Water surface profile}

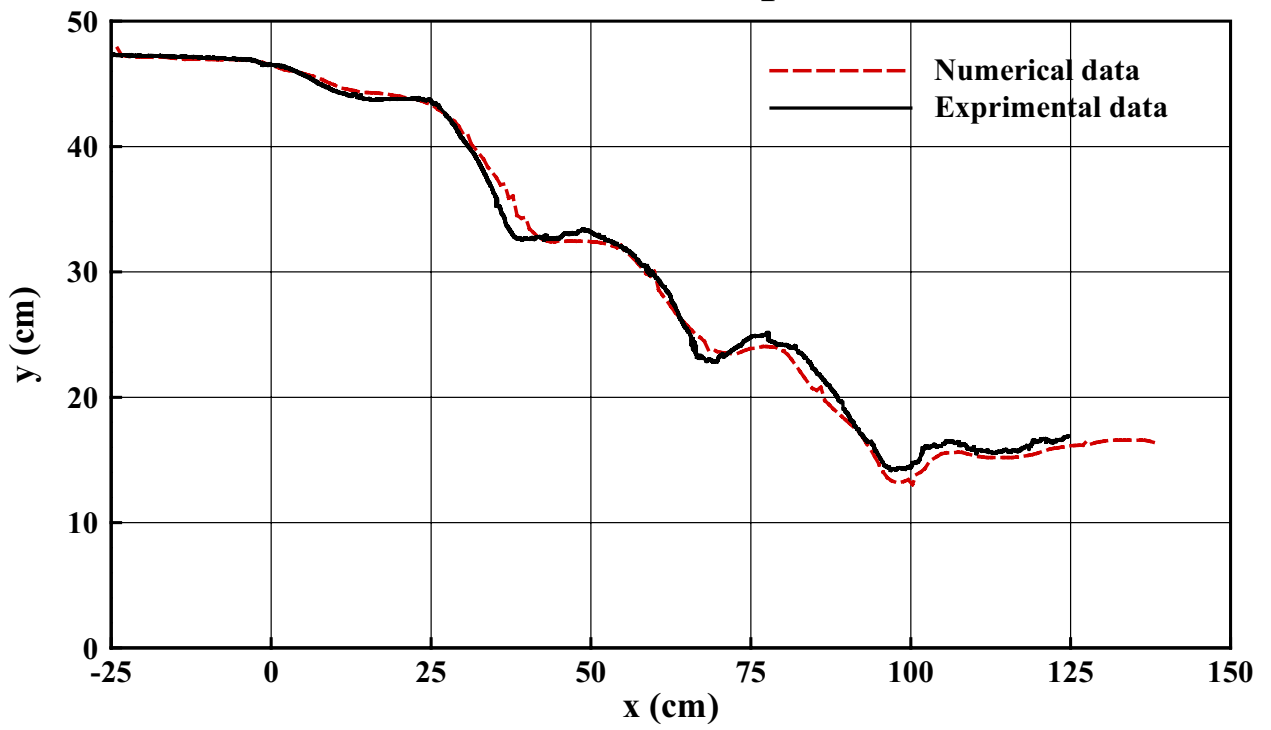




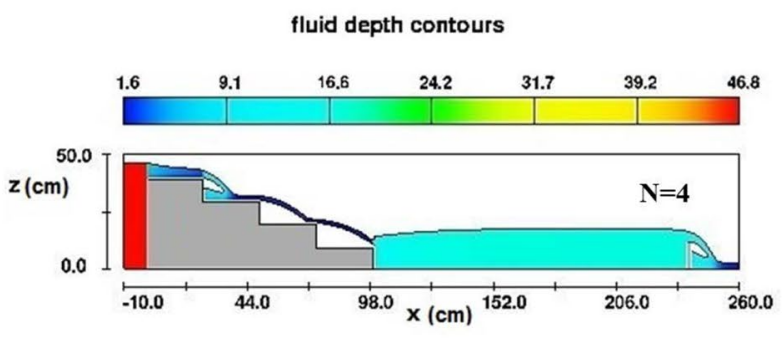

Fig. 8 Flow characteristics over spillways with 4 steps $\left(Q=0.03 \mathrm{~m}^{3} / \mathrm{s}\right)$

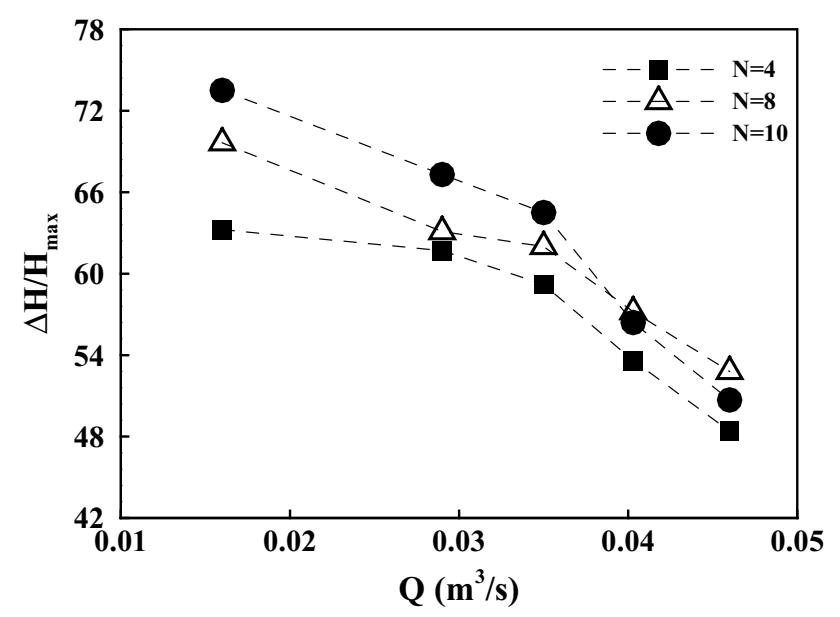

Fig. 9 Comparison of the energy dissipations for models with different discharge rates and steps $(\mathrm{N})$

and height of the step, respectively). The ratio for $h / I$ was equal to 0.4 , so the $y_{c} / h$ for the lower and upper limits of the transition flow can be considered as 0.73 and 1.07 , respectively. Given the dimensions of the model, the capacity of the pump set and consequently the amounts of the discharges, the nappe regime occurred for the studied conditions.

\subsection{Effect of discharge rates and number of steps on energy dissipation}

Three different configurations of steps, five different discharge rates, and subsequently various ratios of critical depth to step height, were considered in order to investigate the relationship between the discharge rates and the energy dissipation. For this study, the calculations showed that a nappe flow regime was established for discharges less than $Q=0.06 \mathrm{~m}^{3} / \mathrm{s}$. The results of the numerical analyses are shown for the energy dissipation versus discharge rates in Fig. 9 and Table 4, with consideration of different numbers of steps.

The results indicate that there is a reasonable relationship between the energy dissipation and the discharge rates. Also, the number of steps has an influence on the energy dissipation, in addition to the discharge values, but the effect of the number of steps is lower for these discharge rates. For most design purposes, a stepped spillway with a constant height can achieve higher energy dissipation by using more steps. The relationships between the energy dissipation and relative critical depth for all step configurations are illustrated in Fig. 10.

As can be seen from the related figures, the energy dissipation rate is decreased by increasing the ratio of the critical depth to the step height $\left(y_{c} / h\right)$ and discharge $(Q)$, while it is observed that the energy dissipation rate increased in different models with the same height by increasing the number of steps $(N)$. Generally, it can be stated that by increasing the number of steps as well as decreasing the discharge (i.e., the dimensionless parameter of $y_{c} / h$ ), the steps produce a retarding effect on the flow in a manner that increases the surface roughness factor, which leads to an increase in the energy dissipation rate.
Table 4 Energy dissipation rates for different numbers of steps

\begin{tabular}{llllll}
\hline Energy dissipation rate & & & \\
\hline $\begin{array}{l}\text { Number of the } \\
\text { steps (N) }\end{array}$ & $\mathrm{Q}=0.016 \frac{\mathrm{m}^{3}}{\mathrm{~s}}$ & $\mathrm{Q}=0.03 \frac{\mathrm{m}^{3}}{\mathrm{~s}}$ & $\mathrm{Q}=0.046 \frac{\mathrm{m}^{3}}{\mathrm{~s}}$ & $\mathrm{Q}=0.04 \frac{\mathrm{m}^{3}}{\mathrm{~s}}$ & $\mathrm{Q}=0.035 \frac{\mathrm{m}^{3}}{\mathrm{~s}}$ \\
\hline 4 & 0.63 & 0.61 & 0.59 & 0.53 & 0.48 \\
8 & 0.70 & 0.63 & 0.62 & 0.57 & 0.52 \\
10 & 0.74 & 0.67 & 0.64 & 0.56 & 0.51 \\
\hline
\end{tabular}




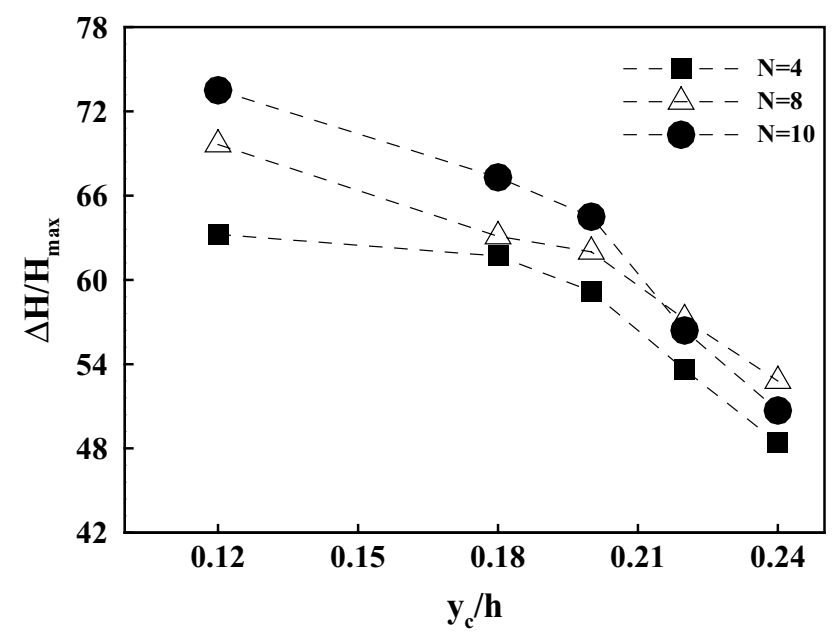

Fig. 10 Comparison of the energy dissipation for different relative critical depths ( $\mathrm{N}=$ number of steps)

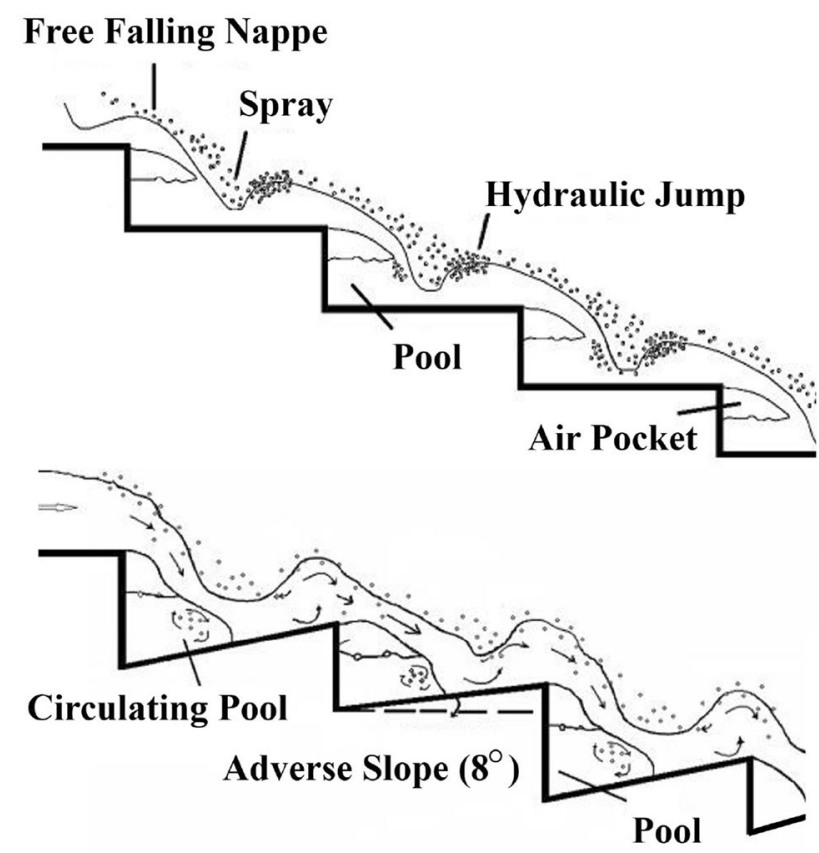

Fig. 11 Effect of negative slopes of steps: a horizontal steps, b negative slopes with circulating pool steps

\subsection{Effect of negative step slope on energy dissipation}

To evaluate the influence of changes in the steps slope, negative slopes of $0,4,8$, and 12 degrees were examined. The fluid flows on the steps with horizontal (i.e., plain stepped spillway) and negative slopes (inclined stepped spillways) are compared in Fig. 11. The figure implies that negative slopes on steps can create circulating pools, which leads to increased energy dissipation rates.
The results for energy dissipation versus the step slope are shown in Fig. 12.

The results show that the energy dissipation of flow over the negative-slope steps was higher than for the plain stepped spillway; i.e., the energy dissipation increased by increasing the adverse slopes. Therefore, an optimum configuration of steps must be assigned in order to reach the best possible energy dissipation rate. Further, the design of the steps must be considered in order to have both maximum energy dissipation and maximum discharge passage.

\subsection{Evaluating the performance of the stepped spillway using FIS}

FIS is a decision-making technique for formulating input-output mapping, using fuzzy logic concepts and IF-THEN rules, along with the logical connectors for drawing hierarchical decision rules.

In order to reduce the time needed for the experimental and numerical modeling of different scenarios, the present work aims to simulate, by a FIS-based method, the effects of geometric parameters on energy dissipation. The optimal configuration of the spillway can be designed using fuzzy logic, which can change the size and slope of the steps with respect to the maximum energy dissipation and optimum discharge passage and feed this to a data-based fuzzy inference system which decides on the pattern of the steps. The performance of the FIS model can be evaluated by comparison with the results of the numerical model. The FIS consists of the three main steps: a fuzzification unit supports the application of numerous fuzzification methods and converts the crisp input into a fuzzy input; a knowledge-based collection of a rule base and database is formed upon the conversion of the crisp input into fuzzy input; and finally, the defuzzification unit's fuzzy input is converted into a crisp output. It should be noted that in this study, the types and ranges of membership functions were chosen by trial and error as well as by considering the physical characteristics of the problem through using numerical and experimental observations.

Data preparation is a very important step in every FIS development, as the success of the FIS is highly dependent on how well the inputs (for this study, discharge rate, number of steps, and negative slope value on each step) and output data (energy dissipation) are represented. Outliers, which are extreme data points that deviate greatly from other data points, must be removed from the data set. Creating the fuzzy rules is another significant and crucial step. The Mamdani system was used to control the energy dissipation rates by synthesizing a set of fuzzy rules obtained from various scenarios, as partially defined in Eq. 7: 
Fig. 12 Comparison of the energy dissipations for different step slopes $\left(\mathrm{Q}=0.03 \mathrm{~m}^{3} / \mathrm{s}\right)$

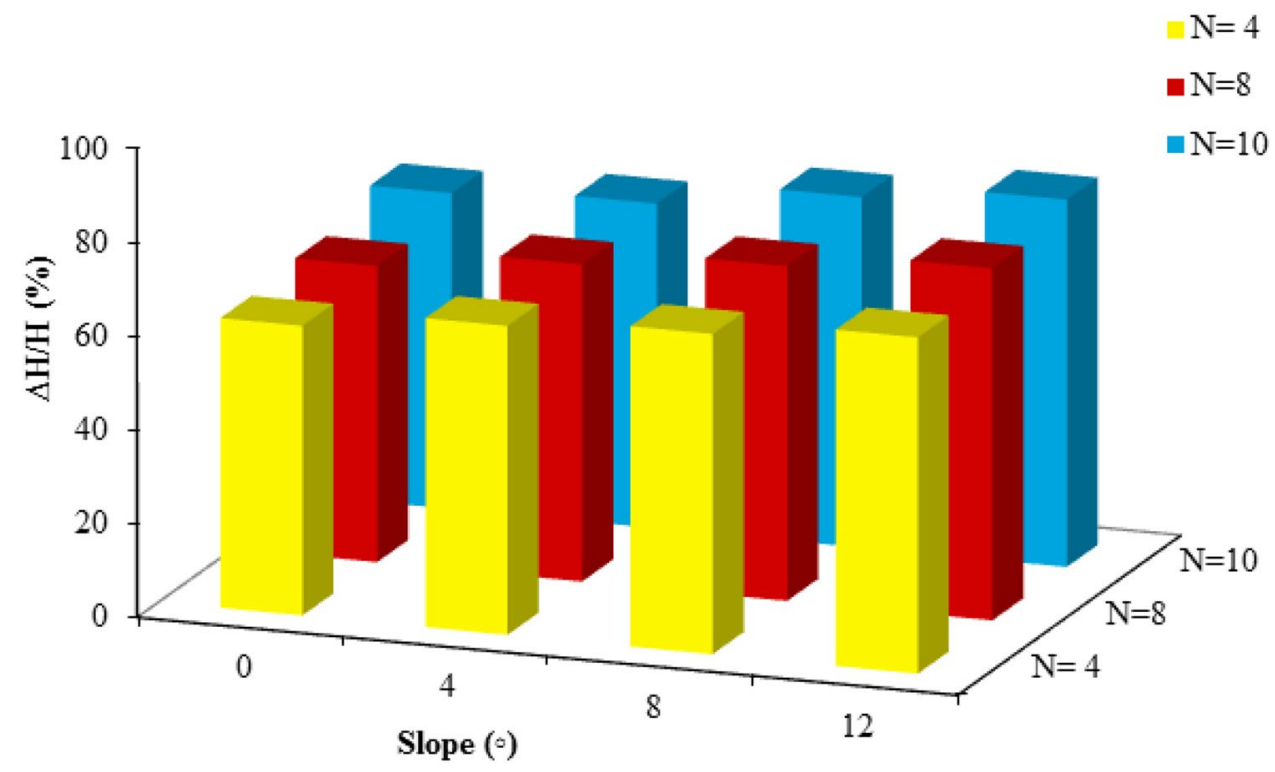

Rulei $^{\text {th }}:$ IF $a, y_{c} / h, N$ are certain linguistic categories THENEDis resultant out

Rule1:IF $\begin{gathered}\frac{y_{c} \text { is High }}{h} \text { is Low } \\ \text { a is Medium }\end{gathered}$ THEN ED is High

A membership function defines the main structure of the fuzzy set by assigning each element a corresponding degree of membership. It relates each point in the input space to a membership value in a closed unit interval $[0$,
1] that defines the degree of truth (e.g., a partial truth instead of, 0 or 1). In this study, the appropriate membership functions were chosen by trial and error in addition to considering the physical characteristics. Commonly triangular, Gaussian, and trapezoidal membership functions were used to develop the fuzzy inference system by using the effective factors $\left(a, y_{c} / h\right.$, and $\left.N\right)$ on the energy dissipation $(E D)$ parameter. The membership functions for all the fuzzy variables were partitioned into 4 linguistic categories, namely: low, medium, high, and very high.
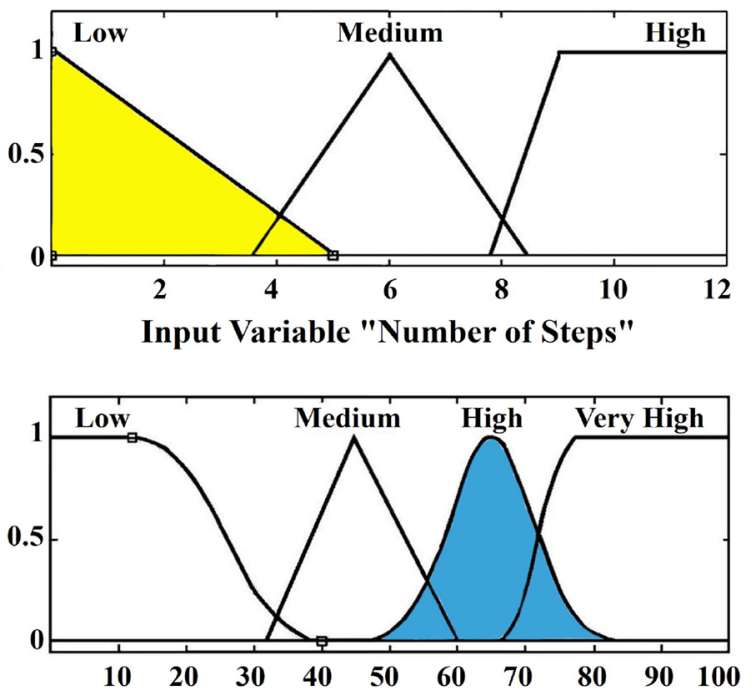

Output Variable "Energy Dissipation"

Fig. 13 A displayed roadmap of the rule viewer for an assumed condition of Rule 1 

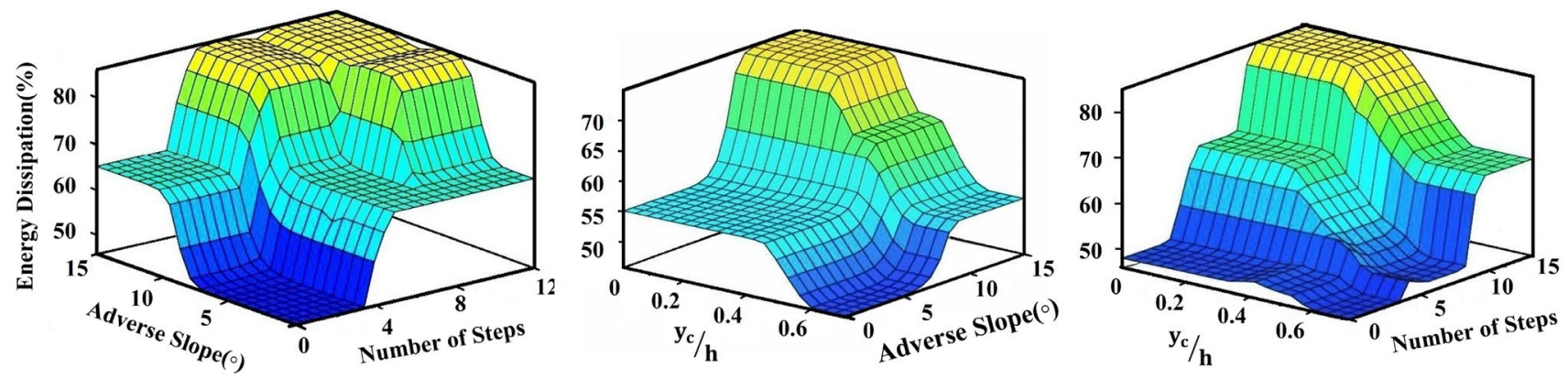

Fig. 14 Fuzzy logic controller using rule viewer for estimation of energy dissipation

Table 5 Energy dissipation values obtained by the FIS and numerical models (flat steps and $\mathrm{Q}=0.03 \frac{\mathrm{m}^{3}}{\mathrm{~s}}$ )

\begin{tabular}{lll}
\hline $\begin{array}{l}\text { Number of } \\
\text { steps }\end{array}$ & $\begin{array}{l}\text { Energy dissipa- } \\
\text { tion (\%) }\end{array}$ \\
\cline { 2 - 3 } & Flow-3D & FIS \\
\hline 4 & 61.7 & 55.2 \\
8 & 63.1 & 65 \\
10 & 67.3 & 65 \\
\hline
\end{tabular}

Trapezoidal membership functions were used for the very high category, while the triangular and Gaussian membership functions were used for the low, medium, and high categories. A sample of rule viewer for membership functions of the input and output variables are illustrated in Fig. 13.

\subsection{Evaluation of classification accuracy using the numerical results and designed FIS}

Figure 14 depicts the fuzzy surfaces according to the energy dissipation rates and the effective inputs given by the FIS model. The figure implies the non-linear relationships between the input and output variables. Also, the surfaces in Fig. 14 indicate that the energy dissipation rate increased by increasing $(N)$ and the adverse slope of the steps, and decreased by increasing the value $y_{c} / h$.

The validated FIS model was used for measuring the estimated energy dissipation rates for different spillway configurations, and the results are compared with the ones calculated by the numerical model (for models with negative steps with an 8-degree slope, $\mathrm{N}=4$, and $\left.y_{c} / h=0.016\right)$. The results in Table 5 are for flat steps and $\mathrm{Q}=0.03 \mathrm{~m}^{3} / \mathrm{s}$, and show the efficiency of the technique in making good predictions within an acceptable error range.

Various classification accuracy criteria are used in confusion matrices to determine the prediction accuracy of the various classifiers. Different kinds of membership functions can undoubtedly impact the performance of
Table 6 Energy dissipation values obtained by the FIS and numerical models (flat steps and $\mathrm{Q}=0.03 \frac{\mathrm{m}^{3}}{\mathrm{~s}}$ )

\begin{tabular}{llll}
\hline Model & Sources & RMSE & $\mathrm{R}^{2}$ \\
\hline GA-SVR & (Jiang et. al 2018) [21] & 7.1859 & 0.954 \\
BPNN & (Jiang et. al 2018) & 8.5574 & 0.9359 \\
ANFIS & (Salmasi and Özger 2014) [33] & 5.7849 & 0.967 \\
BPNN & (Roushangar et al. 2014) [19] & 6.2 & 0.948 \\
FIS & (present work) & 6.74 & 0.955 \\
\hline
\end{tabular}

a fuzzy inference system, and by varying them, the FIS can decrease or nearly eliminate the number of errors. For this study, in order to examine the prediction accuracy of the measured data by the FIS, the mean absolute percentage error (MAPE) was calculated by using all of the data sets, as follows:

MAPE $=\left(\frac{1}{k}\right) \sum_{n=1}^{K}\left|\frac{N_{n}-F_{n}}{N_{n}}\right|$

where $k$ is the number of forecasted scenarios. The parameters $F_{n}$ and $N_{n}$ refer to the values measured by the FIS and the numerical model, respectively. In this regard, the error was calculated at MAPE $=7.8 \%$, which can be considered as an acceptable value based and depending on the particular engineering purposes in the spillway design. The other statistical criteria, including the RMSE and $R^{2}$ values are presented in Table 6.

Table 6 also compares the results of this study with the results of other researchers who used other theories to predict energy dissipation. Although their results show that their prediction accuracies were high, the proposed FIS model can be perceived as a faster method, requiring less time to complete the estimation process due to its shorter iteration procedure. 


\section{Conclusions}

In this study, a fuzzy inference system was developed in order to study the energy dissipation rate of flows over a stepped-type structure. The concepts were evaluated in three parts. Firstly, a physical model of a stepped spillway was used to obtain the experimental results via a laboratory setup. Then, a numerical model was updated based on the observed results, and the model was run for different geometries to prepare a baseline CFD model. Finally, the data gathered were used to scrutinize the performance of the developed FIS model in estimating the energy dissipation parameters.

The following conclusions are summarized. It is observed that the energy dissipation rate is decreased by increasing the discharge rates and consequently the dimensionless parameter of the critical depth to the step height. Also, the energy dissipation rate increased in different models with the same height by increasing the number of steps. This may be related to the fact that decreasing the discharge, in addition to increasing the number of steps, produces a retarding effect on the flow in a manner that increases the bottom roughness factor, which leads to increases in the energy dissipation rate. Furthermore, it was observed that the energy dissipation of flows over negative-sloped steps was greater than over plain steps, and was increased by increasing the adverse slopes. This could be related to the circulating pools formed in the inside corners of the steps.

Lastly, the FIS model was used to measure the estimated energy dissipation rates under different scenarios, and the results were compared with the numerical database. The mean absolute percentage error criteria were used to examine the prediction accuracy of the FIS measurements and were calculated at close to 7.8 percent. The results indicate that the FIS model can be used successfully, with consideration of different geometric parameters. This method is also proposed to consider the uncertainty problems in the literature while considering the benefits. Although the literature notes different but precise methods which use other theories to estimate energy dissipation, the proposed FIS model can be a preferred method because it involves less time to complete the estimation process due to its shorter iteration procedure. The advantage comes from the scheme of designing the frame of the method based on its elaborate membership functions. The above-mentioned results indicate that the proposed FIS model can be used as an efficient tool for the design and operational control of stepped spillways.
Acknowledgments The authors graciously acknowledge Mr. Robert Hart from the University of Ottawa for his review and assistance in improving the language of the paper.

\section{Compliance with ethical standards}

Conflict of interest The authors declare that they have no conflict of interest.

\section{References}

1. Castillo LG, Carrillo JM, Bombardelli FB (2016) Distribution of mean flow and turbulence statistics in plunge pools. J Hydrol 19(2):173-190. https://doi.org/10.2166/hydro.2016.044

2. Frizell KH, Mefford BW (1991) Designing spillways to prevent cavitation damage. Concrete Int 13:58-64

3. Peyras L, Royet P, Degoutte G (1992) Flow and energy dissipation over stepped gabion weirs. J Hydraul Eng ASCE 118(5):707-717

4. Jumaily DKKE, Lami MKA (2009) Study of conveniency of using stepped spillway in roller compacted concrete dams (RCCD). Eng Technol J 27:2964-2977

5. Khatibi R, Salmasi F, Ghorbani MA, Asadi H (2014) Odelling energy dissipation over stepped-gabion weirs by artificial intelligence. M J Water Resour Manag 28:1807-1821. https:// doi.org/10.1007/s11269-014-0545-y

6. Chanson $\mathrm{H}$ (1994) Comparison of energy dissipation nappe and skimming flow regime on stepped chutes. J Hydraul Res, IAHR 32(2):213-218

7. Matos J, Quintela A (1995) Discussion of "jet flow on stepped spillways" by M.R. Chamani and N. Rajaratnam. J Hydraul Eng ASCE 121(5):446-448

8. Felder S, Chanson H (2011) Energy dissipation down a stepped spillway with nonuniform step heights. J of Hydraul Eng. https ://doi.org/10.1061/(ASCE)HY.1943-7900.0000455

9. Matos J, Chanson H (2005) Hydraulic structures: a challenge to engineers and researchers.

10. Barani GA, Rahnama MB, Bagheri H (2005) Optimization of stepped spillway dimensions and investigation of flow energy dissipation over a physical model. J Appl Sci 5:878-882. https:// doi.org/10.3923/jas.2005.878.882

11. Chinnarasri C, Wongwises S (2006) Flow patterns and energy dissipation over various stepped chutes. J Irrig Drain Eng 132(1):70-76

12. Chafi Ch, Abdelkrim H, Seddini A (2010) Study of flow and energy dissipation in stepped spillway. Jordan J Civ Eng 4(1):1-11

13. Parsaie A, Haghiabi AH (2019) The hydraulic investigation of circular crested stepped spillway. Flow Meas Instrum 70:101624

14. AlTalib AN, Mohammed AY, Hayawi HA (2019) Hydraulic jump and energy dissipation downstream stepped weir. Flow Meas Instrum 69:101616

15. Chen Q, Dai G, Liu H (2002) Volume of fluid model for turbulence numerical simulation of stepped spillway over flow. J Hydraul Eng 128:683-688

16. Tabbara M, Chatila J, Awwad R (2005) Computational simulation of flow over stepped spillways. J Comput Struct 83:2215-2224

17. Castillo LG, Carrillo JM Analysis of the Scale Ratio in Nappe Flow Case by Means of CFD Numerical Simulation. In: IAHR Congress, 2013.

18. Parsaie A, Moradinejad A, Haghiabi AH (2018) Numerical modelling of flow pattern in spillway approach channel. Jordan J Civ Eng 12:1-9 
19. Roushangar K, Akhgar S, Salmasi F, Shiri J (2014) Modeling energy dissipation over stepped spillways using machine learning approaches. J Hydrol 508:254-265

20. Roushangar K, Akhgar S, Salmasi F (2017) Estimating discharge coefficient of stepped spillways under nappe and skimming flow Regime using data driven approaches. J Flow Meas Instrum. https://doi.org/10.1016/j.flowmeasinst.2017.12.006

21. Jiang L, Diao M, Xue H, Sun H (2018) Energy dissipation prediction for stepped spillway based on genetic algorithm-support vector regression. J Irrigat Drain Eng 144(4):04018003

22. Schincariol RA, Herderick EE, Schwartz FW (1993) On the application of image analysis to determine concentration distributions in laboratory experiments. J of contaminant hydrol 12(3):197-215

23. FLOW science Inc. (2008) FLOW-3D user's manual, version 9.3

24. Vanneste D (2012) Experimental and numerical study of waveinduced porous flow in rubble-mound breakwaters. Ghent University, Belgium

25. Pope S (2000) Turbulent Flows. Cambridge Univ. Press, Cambridge, U.K.

26. Safarzadeha A, Zajib AH, Bonakdari H (2017) Comparative assessment of the hybrid genetic algorithm-artificial neural network and genetic programming methods for the prediction of longitudinal velocity field around a single straight groyne. App soft comput 60:213-228. https://doi.org/10.1016/j. asoc.2017.06.048

27. Lotfollahi Yaghin MA, Mojtahedi A, Aminfar MH (2012) Physical model studies and system identification of hydrodynamics around a vertical square-section cylinder in irregular sea waves. Ocean Eng 55:10-22

28. Yaghin ML, Mojtahedi A, Ettefagh M, Aminfar M (2011) Experimental investigation of TARMAX model for modeling of hydrodynamic forces on cylinder-like structures. J Mar Sci Appl 10(3):281

29. Li Ch, Mao Y, Zhou J, Zhang N, An X (2017) Design of a fuzzy-PID controller for a nonlinear hydraulic turbine governing system by using a novel gravitational search algorithm based on cauchy mutation and mass weighting. App soft Comput 52:290-305. https://doi.org/10.1016/j.asoc.2016.10.035

30. Jang JSR (1993) ANFIS: adaptive-network-based fuzzy inference system. IEEE Trans Syst Cybernet 23(3):665-685

31. Mojtahedi A, Hokmabady H, Abyaneh SSZ, Nassiraei H (2019) Establishment of a hybrid Fuzzy-Krill Herd approach for novelty detection applied to damage classification of offshore jackettype structures. J Mar Sci Technol 24(3):812-829

32. Chanson $\mathrm{H}$ (2001) Hydraulic design of stepped spillways and downstream energy dissipators. Dam Eng 11(4):205-242

33. Salmasi F, Özger M (2014) Neuro-fuzzy approach for estimating energy dissipation in skimming flow over stepped spillways. Arab J Sci Eng 39(8):6099-6108

Publisher's Note Springer Nature remains neutral with regard to jurisdictional claims in published maps and institutional affiliations. 